Doi: https://doi.org/10.31578/jebs.v6i2.237

\title{
Impact of Human Rights Education at School, Community and Individual Levels - Case Study of Georgia Research Essay
}

Medea Gugeshashvili*

\begin{abstract}
Since its independence in 1991, the promotion of human rights has been a part of Georgia's efforts towards the integration into Euro-Atlantic Institutions. However, difficulties in introducing the concept of individual, democratic and human rights are persistent in the teaching/learning process, as these concepts are still not organic and commonly understood in popular culture. Herewith, a growing level of political and societal polarisation between nationalistic and liberal forces impedes the process of effective promotion of universal human rights principles. The article analyzes the tensions between the core values of nationalism and liberal ideology in Georgia, as well as the supporting factors for the promotion of human rights education (HRE). It discusses the potential of HRE in mitigating the societal polarisation and reaching social cohesion around the basic civic values. A conclusion is made that, despite a considerable progress achieved in promoting HRE in Georgia during the last decade, complexities remain related to the difficulty of introducing the concepts of individual, democratic and human rights in the teaching/learning process, as such concepts are still not organic and commonly understood in popular culture. Based on the best practices identified in various impact assessment studies on HRE worldwide, recommendations are offered for the schools to introduce transformative and emancipatory learning and make HRE effective through the application of the 'wholeschool' approach - an effective tool for bringing tangible changes to the school environment, as well as the impact on the household and community levels.
\end{abstract}

Keywords: human rights education, social cohesion, Georgia, impact of education, wholeschool approach, social cohesion

\section{Introduction}

The article discusses the importance of human rights education for preventing bigotry and discriminatory, xenophobic and homophobic attitudes among students in general education. It analyzes supportive and mitigating factors affecting HRE. The national education policy of Georgia is examined through a historical context and political, cultural and societal perspectives explaining the current status of HRE and the potential for effective interventions. The article discusses to what extent HRE is part of the global education agenda active in the country and the role of global development organizations (e.g. IREX, PH International, USAID, World Bank, GIZ, DAAD, CoE, EC, OSI etc.). The local context analysis provides the extent to which societal values shape the nature of the political process and its outcomes on HRE.

Interventions at the school level are discussed in accordance with Amnesty International project on Human Rights Friendly Schools (HRFS), which entails integrating human rights across a broad spectrum of school life - school governance, relationships (interaction between the members of school community), curriculum and learning environment. The 'wholeschool' approach is

\footnotetext{
* Head of Human Rights Education Department, Office of Public Defender of Georgia Coresponding Email: g_medea@yahoo.com
} 
an effective tool for bringing tangible changes to the school environment. This model offers that human rights are not only learned, but also practiced, respected, protected and promoted.

At the end of the article, an empirical study on social change is provided as an example of the abundance of students and teachers reporting individual and social (household and community-level) changes they had undergone or influenced as a result of specific instructions about human rights. This chapter provides examples on how HRE at school can develop an agency in students as well as educators by having a real-life impact and action-oriented responses. The potential of HRE in achieving of social cohesion at school and societal levels are also discussed after analyzing the level of societal polarization in Georgian society. Finally, recommendations are provided for schools and curriculum developers in promoting HRE at individual school level.

\section{Research Method}

This research is based on the findings of literature review of scholarly articles on critical pedagogy and transformative power of education for democratic citizenship and human rights (EDC/HR). The secondary data analysis also covers the conclusions of longitudinal studies on the impact of HRE on individual, school and societal levels and the effectiveness of the 'wholeschool approach' method to educating on rights - a set of guiding principles and a toolkit developed by Amnesty International. The situation of democratic citizenship and human rights education in Georgia was critically analyzed against the internationally recognized principles and standards on the right of a child to be educated in human rights as defined by a number of EU, COE, and EC regulations, as well as the principles enshrined in the UN human rights conventions and other global documents (ICCPR, ICRC, UDHR, UN Sustainable Goal \#4.7; World Program for Human Rights Education, etc.). The article also provides analysis of the related national legal and policy documents on formal education (laws of Georgia, state strategies and action plans, national reports, etc.).

Furthermore, the essay conclusions and recommendations are drawn based on a subset of the data obtained from the baseline survey conducted in Georgia in 2018 carried out with the purpose to study the situation of HRE in the country. In this survey 360 teachers, 960 students and 140 representatives of school administration from 94 schools were interviewed by the Office of Public Defender of Georgia. The survey tool, a questionnaire, included open, close and semi-close questions. Separate questionnaires were designed for teachers, students and school administration to evaluate their knowledge, skills and values promoting behavior that upholds human rights. On average, 20-22 interviews were conducted in each school, depending on the school size: about 2 representatives of the school administration, 15 students and 6 teachers were selected from each school through random sampling.

\section{Human Rights Education as Part of Global Education Agenda}

"Human Rights transcend national interests and provide the fundamental moral imperative for regulating the contemporary political world order and justifying international intervention in case of human rights abuse" (Landorf, 2009. pp.47-67). Education on human rights was embedded in the major international human rights conventions (ICERD, ICESCR, CEDAW, and CRC).

The UNO Declaration on Human Rights Education and Training (UNDHRET) offers a more specific definition of HRE. According to it, HRE and training comprises all educational, training-based, informational, awareness-raising and learning activities aimed at promoting the prevention of human rights violations and abuses by providing persons with knowledge, skills and understanding and developing their attitudes and behavior, to empower them in order to contribute to the building and 
promotion of a universal culture of human rights (UNDHRET, 2011). It is important to put forward three components (knowledge, skills and approaches) in human rights education.

\section{Education for Democratic Citizenship and Human Rights in Georgia}

The subject of citizenship education was first introduced at schools as a mandatory subject in 2006-07, a number of developmental organizations provided support to Ministry of Education and Science of Georgia (MoES) in promoting the subject. Following the introduction of civic education into the national curriculum in 2006, the National Center for Teacher Professional Development (TPDC), has sought to improve the training of teachers of civic education, for example, social science teachers. Despite these measures, there remain several obstacles to achieving an effective process of teaching and learning human rights. According to the EU and CoE report (2016) on Promoting Education and Democratic Citizenship in the countries of Eastern Partnership (Armenia, Azerbaijan, Belarus, Georgia, Moldova and Ukraine), these challenges are:

a. Insufficient training in applying Council of Europe (CoE) manuals on human rights;

b. shortage of teachers qualified to teach Citizenship Education;

c. Education for Democratic Citizenship and Human Rights Education (EDC/HR) appears to be difficult to comprehend for educational practitioners who received their education in the Soviet period. The idea of democracy as a 'way of life', the role of critical thinking in the process of learning, discussion and debate on contested issues are not seen as necessary attributes of the learning process. The major method of learning remains memorization of facts devoid of critical examination at quite a number of Georgian schools;

d. Schoolchildren are not always familiar with active learning methods of the type recommended for EDC/HR; nor do teachers necessarily encourage students to express their opinions freely in class;

e. The methods and mechanisms of developing students' social and civic competences are not made explicit in the teachers' or school director's professional standards.

A number of other surveys conducted at public schools in Georgia (PDO 2017, 2018) indicate the lack of knowledge, skills and values in human rights among students, teachers and school administration. These reports prove that HRE still fails to have a social cohesive effect at the school and societal levels. The countrywide surveys (PDO 2017, 2018) indicate that schoolchildren and young people at the tertiary education level demonstrate sexist, xenophobic, homophobic and discriminatory attitudes towards ethnic/national and religious minorities, women, LGBTI groups, persons with disabilities and other diverse groups. A considerable number of schoolchildren do not believe in the principle of equality regardless of gender, sex, ethnic/national/religious origin, social status or health condition (see Appendix \#1).

Especially problematic is the issue of violence against children in general education institutions. Based on the regular monitoring performed by the Public Defenders' Office of Georgia (PDO), school administration and educational staff fail to timely identify the cases of violence and provide protection measures. The monitoring conducted by PDO in the 2016-2017 academic year in 109 schools revealed that violence and bullying are widespread in relationships among minors in general educational institutions: $4 \%$ of school personnel and $13.2 \%$ of interviewed schoolchildren do not consider beating as violence; about $40 \%$ of schoolchildren and $13 \%$ of school employees believe that slapping on the head and ear pulling is not violence; attitudes towards various forms of psychological violence are similar (PDO, 2017). Furthermore, the discriminatory values of children and school staff are reflected in the school environment; the monitoring revealed a number of cases of discrimination on the basis of 
ethnic/national origin, religious belief, gender, physical characteristics, academic performance, social status, dress style and other traits (PDO, 2017, p. 162).

School employees and teachers have quite a limited knowledge and skillset for promoting a human rights-based approach in school environment. As the survey of PDO conducted in 2018 in 94 schools indicates, around 46\% of schoolteachers did not study human rights issues either at school or higher education institutions (Appendix \#2). Furthermore, nearly half of the interviewed teachers (48.4\%) had not participated in the teachers' professional development training on human rights or HRE (PDO, 2018, p.35). School administration (principal, vice principal, school chancellor) also displayed a lack of awareness on human rights issues and the strategies or mechanisms used to prevent or cope with discrimination and violence at schools; although around $34-40 \%$ of students say that they are victims of bullying (Appendix \#3), around 95-99\% of school administrators indicate that there are no cases of bullying in their respective schools (PDO, 2018, p. 67). The lack of awareness of discrimination and violence among students, combined with their inaction when they witness such cases, leads them to believe that informing others (teachers, school administration, parents, etc.) will not change anything or could even make things worse - thus children prefer to deal with such cases themselves (Appendix \#4).

\section{Factors Limiting the Effectiveness of HRE in Georgia}

Analyzing the effectiveness of measures used to promote HRE urges us to transcend 'educationism' which views education as a single category with a common scope, shared knowledge and practices (Dale et al., 2007) and consider extra-educational structures, policy trends and regulatory changes, level of democratization, cultural contexts, globalization and internationalization of education, etc. (Verger, Novel, \& Altinyelken, 2012). In Georgia, complexities of EDC/HR are related to a number of factors, including cultural aspects - the difficulty of introducing the concept of individual, democratic values and human rights principles in the teaching/learning process, as such concepts are still not organic and commonly understood in popular culture.

The roots of antagonistic sentiments towards equality principles and respect for minority rights can be partly ascribed to the nationalistic views within the country. 70 years of Soviet rule and policies of assimilation nurtured ethnic nationalism and protective approaches to traditions and culture in Georgia. By the end of the 1980s, this trend was perceived as the only liberating agenda in Soviet republics. As the Lithuanian writer Skomantas Pocius writes, "ethnic nationalism played a crucial role in freeing of all Eastern Europe, as national identities re-emerged, became rallying points of opposition to the Soviet occupation, and then formed the pillars of newly independent nation-states" (Gonzalez, 2018).

The loss of territories as a result of ethnic and political conflicts in two breakaway regions of Georgia - South Ossetia and Abkhazia in the 1990s and 2008 respectively - further intensified the urge for militarism, masculinity, protection of the fatherland, religious nationalism and patriarchal traditions. Some of these values pose an inevitable threat to libertarian principles like gender equality and respect of LGBTIQ groups, migrants and ethnic/national/religious minorities in the country. All this creates a fertile soil for foreign propaganda and fake-news promoting ultra-right movements and anti-Western values (Gordon, 2020).

Georgia, similar to a number of modern states all over the world nowadays, faces difficult challenges: trust in democratic processes has lessened and the last several years have witnessed the emergence of ethnic nationalism among youth. The reasons behind these developments in many countries are mainly related to economic crisis, unemployment and lack of opportunities, immigration from developing countries and the influx of refugees from the Middle East and the Levant (Greven, 2016). Ethnically and linguistically homogeneous areas tend to be less tolerant of people with different cultural backgrounds, which results in the lack of integration of those arrived, segregation and intolerance of immigrant communities. 
Another factor contributing to the resistance of assimilating universal human rights principles through education is the strong influence of the Christian Orthodox Church in the country, which for the last few decades Georgians evaluated as the highest-performance ranking establishment, a plurality (46\%) even believing the Church should have influence on political decision-making. Due to the pressure of the Church, the issue of non-discrimination based on gender identity was removed from the National Curriculum of Georgian secondary education (DIHR, 2010; Antelava, 2015).

In addition to these factors, it is the general inclination of states (especially countries with authoritarian and posttotalitarian histories of governance) to restrain from promoting human rights. Awareness of rights and responsibilities are perceived as threat by the states in comparison with other, more standard domains of education (Cardenas, 2005). HRE aspires partly to end and prevent the abuses committed, perpetuated, and tolerated by states. "If successful, members of society may challenge the state openly, defying potential abusers or demanding punishment for violators and compensation for victims" ( $p$. 365). Human rights are often perceived as having an inherent limiting power for governments. "The most effective check against tyranny is a public consensus on the definition of tyranny; on the rights of those who believe they are the objects of tyranny; and on the obligations and responsibilities of those who use coercive power" (Heyneman, 2020).

Thus, though Georgia's liberal politicians say only alignment with Europe and the US will allow the country to overcome its post-Soviet past and survive as an independent nation, in reality there is a lack of political will among the government to confront far-rights extremism - the country's anti-Western powers obstructing the formation of tolerant and peaceful communities (Gordon, 2020). An increasingly influential Orthodox Church, often associated with having ties with Russia's Orthodox Church (Trippe, 2019; Antelava, 2015) and ultra-right, nationalistic groups portraying the West as decadant use schools to breed a generation of religious conservatives, with nationalistic values whose beliefs are very opposite to the West's (Antelava, 2015).

\section{HRE as an Effective Tool for Social Cohesion}

Only a community with a high level of education and awareness of others' rights can mitigate these problems. While HRE is not a panacea that can solve all the problems instantly, it is the only way to create a responsible society where people are aware of their social status and role in society (EC, 2017).

Georgia's political environment is characterized by an extreme level of polarization, which penetrates different social contexts and affects the daily reality of many people (DRI, 2018). It is due to this polarization that people refrain themselves from committing to a cause or even expressing their opinion in case it contradicts the ideology of a political party or a social institution, which they associate themselves with (DRI, 2018). In such an environment, the principles of democracy and human rights are subjects of debate and politically instrumentalised (DRI, 2018). NGOs and civil society organizations promoting human rights and rule of law often indicate about the difficulties of operating in this highly polarized society (DRI, 2018).

The societal polarization enhances us-versus-them identity politics and affects the interpersonal relationship between ordinary citizens dividing society into two camps that hardly interacting with each other on a number of issues (DRI, 2018). This polarization appears around the values of multiculturalism, respect of minority rights, migrant issues, religious, traditional and national values; international relations are seen through stark differences of Eurosceptic (often promoting the idea of 'normalizing the relationships with Russia') and the pro-Western population.

In parallel with the ultra-rights groups a new wave of youth with liberal values emerged in Georgia. The catalyst of protests came during the upheaval of June 20, 2019, when the ruling Georgian Dream party invited the Russia communist politician Sergey Gavrilov and a delegation from Moscow to address Georgia's Parliament. As Russian soldiers currently occupy internationally 
recognized Georgian territory, the move did not go down well. After an indiscriminate aggressive rally of police over the protesters, the crackdown triggered even bigger rallies for more than two months in front of the Parliament of Georgia (Kincha, 2020). What unites these protesters dominated by youth is the Western orientation in international politics, critics towards collaboration with the occupant country, demands to introduce the proportionate electoral system and the liberal values including the respect of the basic human rights values and tolerance. The polarization between this youth and the ultra-right groups became very evident and reached a dangerous point of clashes during the protests in June 2019, which was fortunately prevented by the police.

\section{Transformative Power of HRE at School Level}

The necessity of supporting HRE on several levels is portrayed by a number of surveys, which evidence that it is not sufficient to provide the knowledge on human rights, but also education shall develop a respective set of values and skills to uphold the rights of self and others. Furthermore, the human rights-based approach shall be mainstreamed in the school management process to ensure the rights-friendly learning environment. Taking non-discrimination and bullying as an example, there shall be some mechanisms in place within the school administration to enable children to report on these cases.

The surveys conducted in the schools of Georgia in 2017 and 2018 reveal the same trend - reluctance of children to respond to violence and bullying at school due to the absence of proper mechanisms within the schools, which would make it safe and effective for the children to communicate these cases.

The experience of the Canadian empirical assessment of HRE can be used in Georgian context to advocate for the improvement of HRE in the current "New School" reform framework. The survey of 2001 compared schools which fully incorporated the HRE program Rights, Respect and Responsibility (RRR) (Covell \& Howe, 2005) with those in which it was less fully incorporated the following outcomes were found.

Among the pupils of all age groups were:

1. Improved academic achievement including critical thinking, self-confidence in dealing with new tasks, improved test scores; also, safe and more friendly social interaction and constructive behavior were reported;

2. The cases of disruptive behavior decreased, pupils expressed more respect and helpfulness towards others;

3. More respectful behavior was observed towards the school environment, less cases of damaging school equipment, vandalism and graffitti were reported as well;

4. Increased number of pupils participating in the classoom and extra-curricular activities and clubs was observed;

5. Teachers reported reduced level of professional burnout.

\section{'Wholeschool Approach'}

One of the most effective tools for social cohesion at school level is mainstreaming HRE through 'wholeschool approach,' which implies tailor-made decisions for individual schools in promoting HRE in several key areas of school life.

These areas elaborated by the Amnesty International (2017) are:

1. Governance - school management, including formal and informal process of decision-making;

2. Relationships - interaction between the members of school community;

3. Curriculum - content and methodology of teaching human rights;

4. Environment - school climate, setting in which people learn. 
The above-mentioned areas are not mutually exclusive and overlap in everyday school activities; however, their individual consideration facilitates the process of integrating human rights principles and mechanisms at each of the realms of school life. The progressive realization of human rights should ultimately aim to respect, protect and fulfill these rights in all four areas.

Amnesty International's Human Rights Friendly Schools (HRFS) project started in 2009 and currently covers 22 countries around the world. HRFS is a framework promoting the principles of tolerance, non-discrimination, respect to diversity, inclusion, participation and empowerment. It is a school community where human rights are promoted, protected, taught, learned, respected and practiced (Amnesty International, 2017).

HRFS approach implies not only inculcating human rights principles in theory, but also mainstreaming and practicing them in school life in an inclusive way and without discrimination. It encourages respect for cultural diversity, dignity and integrity in the classrooms and beyond them, in all aspects of school life. Thus, HRFS, which is also commonly referred to as a 'wholeschool approach,' a 'holistic approach' or 'rights-based approach', becomes a catalyst for change on individual, school and wider community levels.

The HRFS implies putting in practice the global principles developed based on the major instruments of human rights ${ }^{5}$ : learning environment where the human rights are respected, protected and promoted; inclusive and non-discriminatory environment; free participation in school life, including defining school policies and practice; accountability and transparency of policy-making processes; shared responsibility of school community to ensure safe and secure environment; mainstreaming human rights into all aspects of teaching and curriculum; empowerment of all students to reach their full potential and empowering students to become active members of global community.

Application of these principles to schools requires the involvement of all members of school community - students, teachers, administrators, non-teaching staff, parents and families. This implies mutual cooperation and consensus on common values among all parties involved, which can be a big obstacle, as there is no common agreement and social cohesion in the highly polarized Georgian community around the purpose of education and the values it shall promote. Furthermore, as discussed above, it can be hard for educators and school staff to apply the HRFS principles in practice, as the majority of them received their education and professional experience in the Soviet and post-Soviet period and are accustomed to formal educational setting, which discouraged individualism, creative and critical thinking.

\section{Critical Pedagogy and Transformative Model of HRE}

Promotion of HRE at the school level can have a transformative power on students empowering teachers to choose the right model for HRE which can be instrumental in obtaining results in the short-term perspective. In the long-term, this empowerment contributes to framing communities as respectful towards diverse groups and encouraging of participation in democratic processes.

The citizenship function of HRE implies transcending curriculum and achieving social cohesion, which can lay a foundation of stable democracy (Heyneman, 2003). HRE promotes shared values and a common understanding of humanity, while simultaneously appreciating the diversity of culture and the necessity for individuals to express and pursue their own articulated needs (Tibbitts, 2017). This requires teaching methods that are emancipatory and develop human agency.

Tibbitts (2017) reviews the HRE models - participatory (applying human rights values to issues at hand) and empowering

\footnotetext{
${ }^{5}$ The UDHR; ICERD; ICESCR; ICCPR; CEDAW; CAT; ICRC; ICRMW; ICRPD; The UNO Declaration on Human Rights Education and Training; Regional human rights instruments.
} 
(knowledge on the rights and the mechanisms to protect them is empowering itself) and puts a special emphasis on the third model - the transformative and emancipatory learning approach. This approach implies a critical analysis of social context and the underlying reasons of one's individual problems at micro (family, household) or macro (community, country) levels. It develops an agency in students to take action against the oppression in their families or immediate environment, which can trigger human rights activism and ultimately result in the social change.

The method of transformative and emancipatory learning is associated with critical pedagogy. According to Freire (1970/1990), liberating and problem-solving education develop critical thinking in students; this type of education "bases itself on creativity and stimulates true reflection and action upon reality, thereby responding to the vocation of persons as beings who are authentic only when engaged in inquiry and creative transformation" (p.71). For Freire, critical education is emancipatory, empowering and thus a necessary element for democratic society with an active civil society. According to him, it is the critical citizens - not the naïve, irrational people - who can perceive the challenges of their time, reflect on them, resist suppressive, paternalistic forces and bring progressive change (Freire, 1973).

Critical pedagogy is crucial for teaching human rights. As the main essence of HRE is to challenge traditional perceptions of societies which can be harmful to its members, it equips students to be perceptive of any tendency characteristic of totalitarian, oppressive governments and empowers them to challenge it. Therefore, the critical learning method continues to be associated with the HRE Transformation Model, as this model focuses on emancipating and empowering students to overcome internalized oppression (Tibbitts, 2017).

\section{Transformative Power of HRE at Societal Level}

For developing student agency and motivating them to act, the relevancy of teaching shall be ensured by analysing the current cases of human rights violations and how they affect the community including the lives of individual students, so that they identify self-interest by improving the rights situation. According to Goodman (2000), self-interest nurturs empathy and understanding that promoting and protecting human rights brings benefits to self as well as to others; this understanding mitigates against attitudes and belief that confuse charity with social justice.

The survey - Schooling for Social Change: The Rise and Impact of Human Rights Education in India - provides an empirical study over the period of 13 months in over 4000 schools in India (Bajaj, 2012). The research revealed an abundance of students and teachers reporting individual, social (household and community-level) changes they had undergone or influenced as a result of specific instruction about human rights:

- Middle age students confronted abusers and found ways to intervene in or reporting abuses

- Students sacrificed their own relative privileges to stand in solidarity with those less fortunate

The impact of HRE on the students at Indian schools can be categorized in four areas:

- 1) students intervening in the situations of abuse to assist the victim either at domestic or community levels;

- 2) increased cases of reporting abuse - after identifying the human rights violations, students reported or threatened to report to respective authorities;

- 3) students raising awareness or educating others on human rights;

- 4) changing attitude or behavior of students, e.g shifting their perception on gender roles, such as a seventh-grade boy who started cleaning his dishes rather than having his sister do all the plates as was done previously. 


\section{Conclusion and Recommendations}

Despite a considerable progress achieved in promoting HRE in Georgia during the last decade, complexities remain related to the difficulty of introducing the concepts of individual, democratic and human rights in the teaching/learning process, as such concepts are still not organic and commonly understood in popular culture. While liberal and pro-Western political and societal forces promote human rights principles, the effectiveness of HRE is counteracted by ultra-right and nationalistic groups and institutions halting the process of dissemination of universal human rights principles through education. The tension between the core values of Georgian public ideology has an impact on the State education policy, which seeks to achieve balance and stability, often at the stake of compromising the education on the universal principles of non-discrimination and equality.

The high level of societal and political polarization between conservatives and liberals results in the absence of agreement on the issue of civic education and teaching human rights as beneficial. The lack of consensus and coherence in promoting HRE for the common social good at macro level can be mitigated through the interventions at micro - school - level. Transformative and emancipatory learning approaches as well as the application of 'wholeschool' approach to HRE can be effective for inculcating human rights culture. As the surveys conducted in Canada and India demonstrated, holistic approach and critical pedagody have a positive impact on the school climate as well as on the household and wider community. The experience of these countries could be replicated and adjusted to the Georgian context for promoting peace and respect for diversity at school and community level. The current New School Reform, giving more independence to schools in making decisions provides a supportive environment for these interventions. For promoting HRE at micro level, several recommendations could be identified for schools and curriculum developers:

1. In order to mitigate the public mistrust, apathy and disinterest in the notion of human rights, as well as to avoid a formalistic recognition of universal human rights principles, curruculum developers shall move classroom-based activities into a more inquiry-oriented dimension. For example, the formal principles of equality and nondiscrimination will be deconstructed by linking them to students' personal experience and their sense of empathy and solidarity. It will be also effective to 'domesticate' the universal human rights principles through finding relevant references in traditional Georgian culture (writings, arts, publicistics, etc.), which are widely accepted by Georgians and at the same time are questioning of outdated beliefs held by communities against a greater humanity that trascends the meerly parochial. Literary writing and art works of revered Georgian writers and artists contain an ample of references to tolerance, non-discrimination and other liberal values;

2. Promote democratic culture and human rights based-approach in the classroom and school management. Although knowledge on human rights and values can be transferred to some degree through didactic instructional methods, education for critical citizenship requires that the classrooms develop habits of critical thinking and reflection, as well as skills related to problem solving and conflict management;

3. It is imperative that there are human rights protection mechanisms embedded in the school management process, as the principles promoted during classroom discussions become best ingrained in students when their envoronment is reinforcing these principles through their actual adherance and practical implementation;

4. Create a platform of cooperation with civil society organizations to encourage extracurricular and voluntary activities where students will develop the skills and bahavior necessary for protecting and promoting human-rights values in their communities. 


\section{References:}

Amnesty International. (2017). Human Rights Friendly Schools - Toolkit. Retrieved from

https://www.amnesty.org/download/Documents/POL3266092017ENGLISH.PDF

Antelava, N. (2015, May 7). Georgia: Orthodoxy in the classroom, BBC News. Retrieved from https://www.bbc.com/news/worldeurope-325955

Bajaj, M., 2012. 'Schooling for Social Change - The Rise and Impact of Human Rights Education

in India', International Journal of Education Development. Retrieved from: https://www-sciencedirectcom.proxy.library.vanderbilt.edu/science/article/pii/S0738059310001409

Cardenas, S. (2005). Constructing Rights? Human Rights Education and the State. International Political Science Review, 26(4), 363379.

Covell, K. \& Howe, R.B. (2005). Rights, Respect and Responsibility. Report on the RRR Initiative to Hampshire County Education Authority. Nona Scotia, Canada: Cape Brenton University.

Dale, R. \& Robertson, S. (2007). Beyond methodological 'isms' in comparative education in an era of globalisation'. In A. Kazamias \& R. Cowan (Eds). Handbook on Comparative Education. Netherlands: Springer, pp.19-32.

DIHR (Danish Institute for Human Rights). (2010). Study on Homophobia, Transphobia and Discrimination on Grounds of Sexual Orientation and Gender Identity Sociological Report: Georgia, $2010 . \quad$ Retrieved from: https://www.coe.int/t/Commissioner/Source/LGBT/GeorgiaSociological_E.pdf

DRI (Democracy Report International) (2018). The High Price of Extreme Political Polarization in Georgia (report). Retrieved from: https://democracy-reporting.org/dri_publications/the-high-price-of-extreme-political-polarisation-in-georgia-report/

European Commission (2017). Eurydice Brief: Citizenship Education at School in Europe. pp. 3-4. Retrieved from https://op.europa.eu/en/publication-detail/-/publication/e0f2801c-184c-11e8-ac73-01aa75ed71a1/language-en

Freire, P. (1990). Pedagogy of the oppressed. New York, NY: Continuum Press. (Original work

published in 1970).

Freire, P. (1973). Education for critical consciousness. New York: Seabury Press.

Gonzalez, G. (2018, November 8). Ethnic Nationalism Gave Georgia Freedom. Now it Needs Civic Nationalism to Survive. EP News. Retrieved from: https://foreignpolicy.com/2018/11/08/ethnic-nationalism-gave-georgia-freedom-now-it-needs-civicnationalism-to-survive-russia-putin-ussr-caucasus/

Goodman, D. J. (2000). Motivating people from priviledged groups to support social justice. Retrieved from https://www.researchgate.net/publication/249400242_Motivating_People_from_Privileged_Groups_to_Support_Social_Ju stice

Gordon, A. (2020). Reflections on Ukraine, Georgia and Armenia, Special report 2020, Freedom House. Retrieved from: https://freedomhouse.org/report/special-report/2020/new-eurasian-far-right-rising 
Greven, T. (2016, May). The Rise of Right-wing Populism in Europe and the United States, A Comparative Perspective; Friedrich Ebert Stiftung. $\quad$ Retrieved from http://dc.fes.de/fi http://dc.fes.de/fileadmin/user_upload/publications/RightwingPopulism.pdf

Heyneman, S.P. (2020). Social Cohesion and Education. Encyclopedia of Education. Retrieved from: https://education.stateuniversity.com/pages/2428/Social-Cohesion-Education.html

Heyneman, S.P. (2003). Education, Social Cohesion, and the Future Role of International Organizations. Peabody Journal of Education, 3(4), 73-97.

Kincha, S. (2020). Georgia's Youth Protesters Lead 2020's Political Showdown. Global

Voices. Retrieved from https://globalvoices.org/2020/03/02/georgias-youth-protesters-at-the-forefront-of-a-politicalshowdown/

Landorf, H., (2009). Toward a philosophy for global education. In T. Kirkwood-Tucker (Ed.).

Visions in global education: The globalization of curriculum and pedagogy in teacher education and schools. New York: Peter Lang Publishing. pp.47-67

Public Defender (Ombudsman) of Georgia. (2018). Survey on Human Rights Education and Educational Environment in General Education Field. Retrieved from https://ombudsman.ge/geo/spetsialuri-angarishebi/kvleva-adamianis-uflebebisswavlebisa-da-saswavlo-garemos-shesaxeb-zogadsaganmanatleblo-sivrceshi

Public Defender (Ombudsman) of Georgia. (2017). Annual Report of the Public Defender of Georgia. The Situation of Human Rights and Freedoms in Georgia. Retrieved from https://ombudsman.ge/res/docs/2019062409381039906.pdf

Tibbitts, F. (2017). Revisiting 'Emerging Models of Human Rights Education'. International Journal of Human Rights Education, 1(1), $1-24$.

The UNO (1948, December 10). Universal Declaration of Human Rights. Retrieved from https://www.un.org/en/udhrbook/pdf/udhr_booklet_en_web.pdf

Trippe, C. (2019, June 26). Opinion: Georgia Caught up in Russia's Political Power Struggle. DW News. Retrieved from: https://www.dw.com/en/opinion-georgia-caught-up-in-russias-geopolitical-power-struggle/a-49316846

UNDHERT. (2011). United Nations Declaration on Human Rights Education and Training

(Adopted by the General Assembly, Resolution 66/137, A/RES/66/137, 19 December 2011). Retrieved from:

https://www.ohchr.org/EN/Issues/Education/Training/Compilation/Pages/UnitedNationsDeclarationonHumanRightsEducationan dTraining(2011).aspx

Verger, A., Novelli, M., \& Altinyelken H.K. (eds). Global Education Policy and International Development, New Agendas, Issues and Policies, Bloomsbury Academic 2012. Retrieved from: https://www.bloomsburycollections.com/book/global-educationpolicy-and-international-development-new-agendas-issues-and-policies/ch1-global-education-policy-andinternational-development 


\section{Other resources:}

Minister of Education and Science of Georgia. Order \#48, 18 January 2019. "Supporting Basic Education Reform", Reform of "New School Model"

Council of Europe. (2016). Report on education for democratic citizenship and human rights education policy and practice in six eastern partnership countries. (2016). Retrieved from: https://rm.coe.int/1680703cf8 
Appendix \#1

\section{Diagram \#1 - Level of Tolerance Among School Children}

1) Believes that learning with ethnic or other minorities creates conflic situations

2) Don't believe that students with disabilities can become successful at learning

3) Denies the idea that religious minorities promote diversity at school

4) Considers that the PWDs at school impede education process

5) Don't share the universal principle of

6) Can't express his/her opinion freely at school

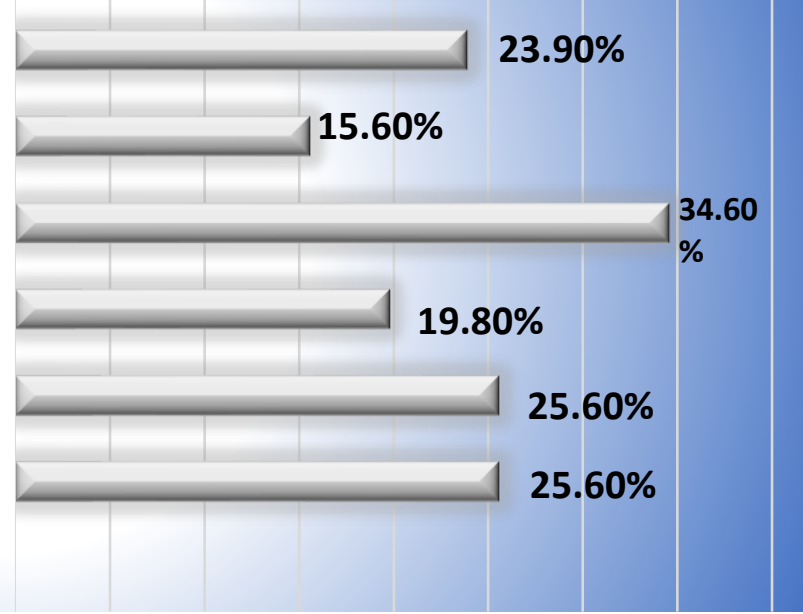

Available at: https://bit.ly/3pQJaof

\section{Appendix \#2}

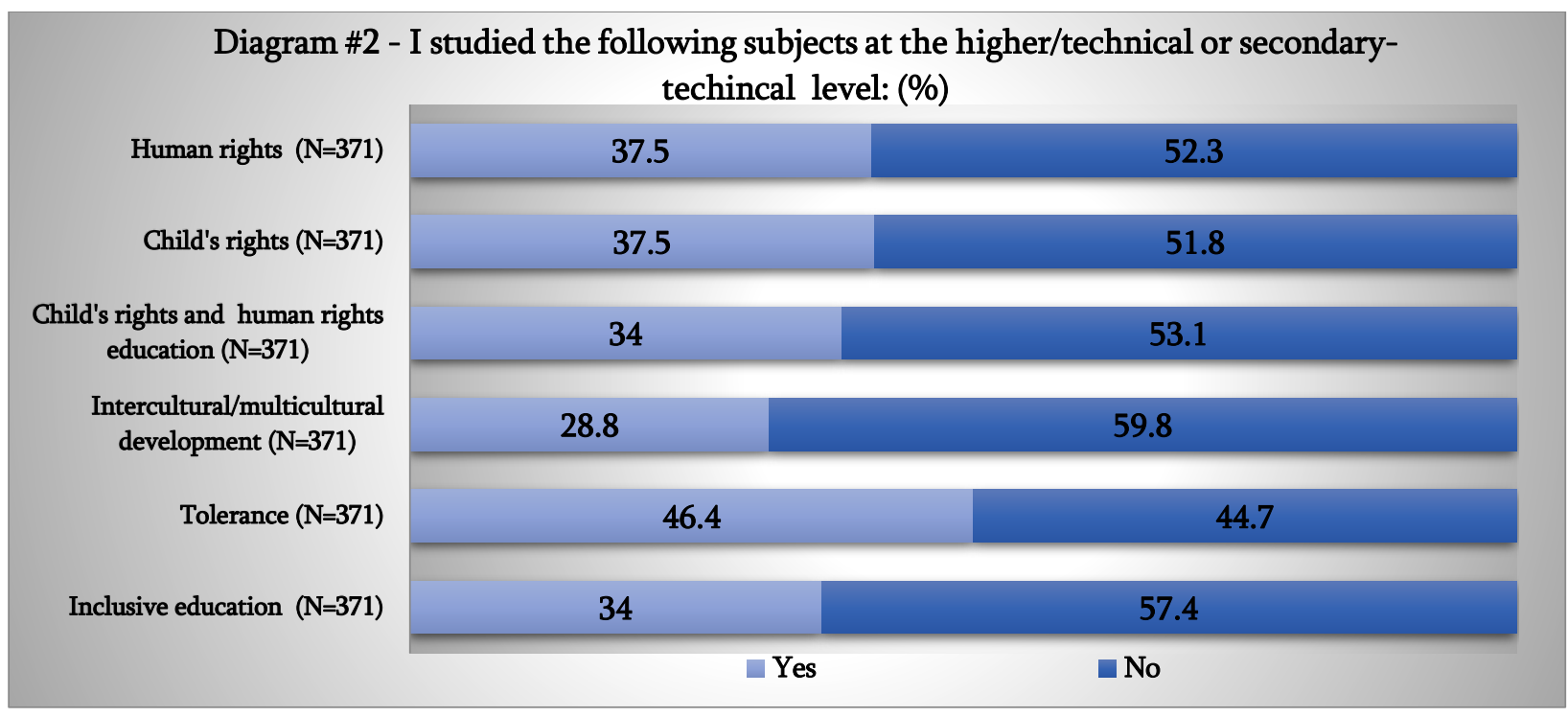

Available at: https://ombudsman.ge/res/docs/2019111314180332627.pdf 


\section{Appendix \#3}

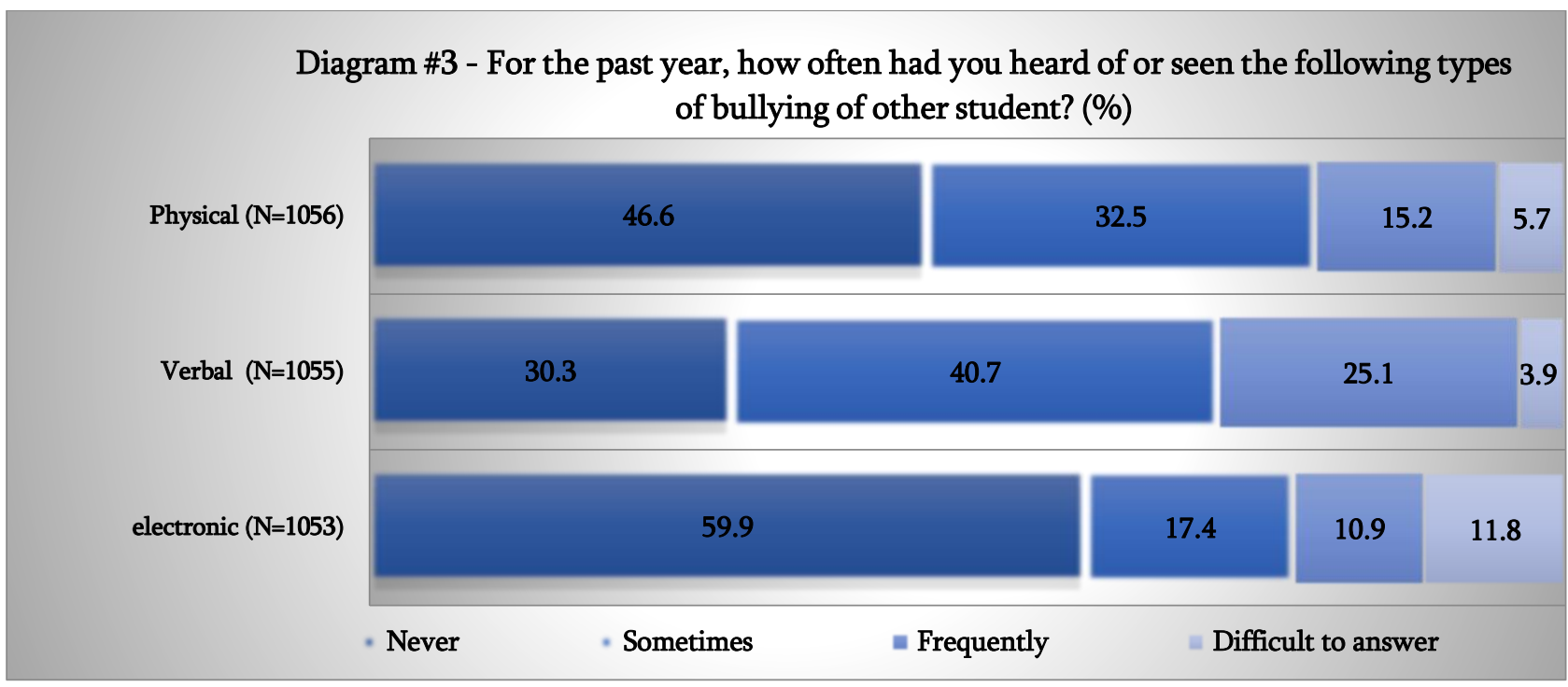

Available at: https://ombudsman.ge/res/docs/2019111314180332627.pdf

\section{Appendix \#4}

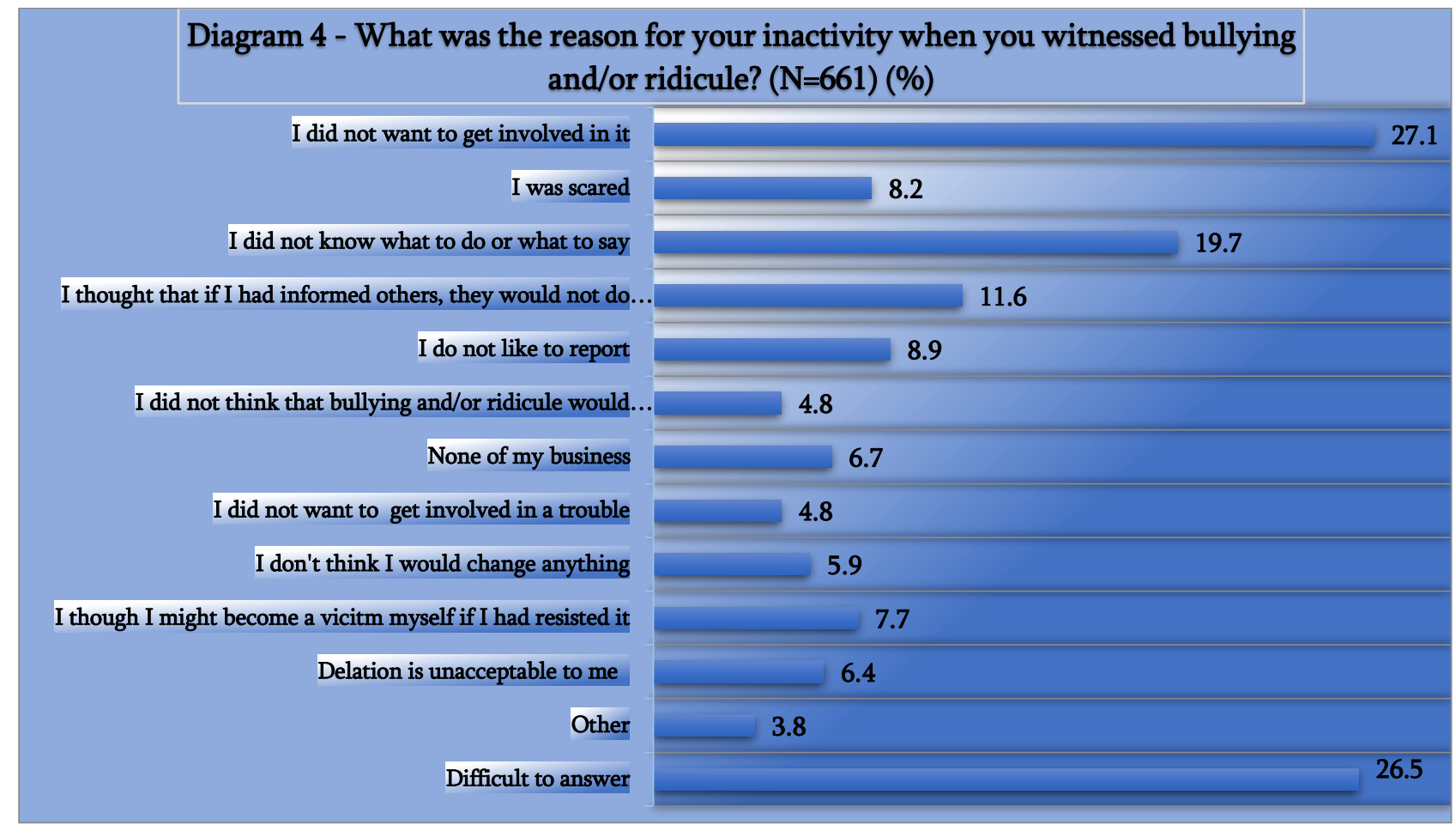

Available at: https://www.ombudsman.ge/res/docs/2019111314180332627.pdf 